\title{
Analysis of organizational conditions for risk management: the case study of a petrochemi- cal site
}

\author{
Corinne Gaudart ${ }^{\mathrm{a}}$, Alain Garrigou ${ }^{\mathrm{b}}$ and Karine Chassaing ${ }^{\mathrm{c}}$ \\ ${ }^{\mathrm{a}} \mathrm{CBRS}$ - LISE/CREAPT - 55, rue Turbigo 75003 Paris (France). corinne.gaudart@cnam.fr \\ ${ }^{\mathrm{b}}$ Deparment HSE, IUT Bordeaux 1,15 rue Naudet 33175 Gradignan (France), alain.garrigou@u-bordeaux1.fr \\ cDeparment Ergonomie, ENSC-IPB, 146 rue Léo Saignat 33066 Bordeaux (France), karine.chassaing@ensc.fr
}

\begin{abstract}
This paper presents an ergonomic intervention in the petrochemical sector. The scheduled shutdown of one of the gas production sites has led the management to reduce the number of personnel on site, and then to get new recruits and experienced technicians from other sites as the policy for leaving personnel had not been properly planned, resulting in understaffing on site. Workers with seniority on the site, and who are also the most experienced do not accept the way newcomers are induced on site, whereas the management accuses them of resisting change. The intervention consisted in reconnecting local and corporate management through making the work activity visible and linking two sets of data that they held separately. Different types of analyses were made, work demography, decision making processes and tools used by the management, analysis of the building of career and work logics. Those different levels of analysis are gathered in macro-ergonomics, while showing the possible combinations between top down and bottom up approaches. The intervention resulted in concrete changes: HR simulation tool, training organisation, feedback.
\end{abstract}

Keywords: macroergonomics, reliability, high hazard industry, activity ergonomics four, demography of work. 


\section{Introduction}

This paper presents an ergonomics project which occurred in the petrochemical sector in 2008. The context was peculiar as this sulfur gas production site is to be shutdown in 2013 because the gas pocket will then be depleted. The decrease in production is accompanied by a decrease in site personnel. Retirees are not replaced and staff that are not near retirement are generally encouraged to transfer to other sites.

These measures actually lead to understaffing. Resorting to new or inexperienced workers creates strong dissatisfaction among production personnel; so much so that they refuse to welcome new workers. It has been impossible for management on the one hand and unions and workers on the other to communicate. This is why the senior management has asked ergonomists to come on-site and "help lift change resistance among employees whose behaviour at work can pose risks for the safety."

\section{Methodology}

Different dimensions of work can be seen in the management's request: age, seniority, and professional history but also that of occupational and industrial hazards. The objective of the intervention is to combine those dimensions so as to improve the site's organisational reliability. We used three types of analyses.

\subsection{Analyses in work demographics}

The point is to combine data pertaining to the characteristics of the workers (age, seniority, status) to data relative to production [1] so as to create a map of work demographics. These different sets of data are often processed by separate services with distinct agenda. Data on people are gathered and used by HR to solve qualifications and employment issues. Data on production and its management can be found in other departments and focus on performance, quality or safety. Replying to such questions as "who's leaving when? From which service? With which skills?" requires specific analyses that cannot a priori be found in the company's present resources.

Leading these analyses through time also makes it possible to understand the organisational and demographic changes that the company has been through. Completing synchronic ergonomic analyses with that diachronic approach will enrich the perspective on work and what the stakes really are.

\subsection{Management strategy analyses}

The context of the intervention points from the setout to the management of employment, staff, production and safety which all imply senior executives at group level as well as local managers on site.

With this in mind, different interviews were made:

- with members of the management, individually and collectively - director, deputy director, technical directors, HR, occupational doctor - so as to understand the staff management decision making processes;

- with local management from the production service and operation supervisors who work on shift so as to understand their constraints in terms of staff management as well as the tools they use;

- with union representatives so as to understand their own decision-making processes faced with the organisational changes brought about by managers.

A steering committee with representatives from the three above groups was created to follow up on the results and agree on the changes in the framework of a GPEC agreement (Forward-looking Employment and Skills Management).

\subsection{Ergonomics work analyses}

Focused on the comprehension of real work activity [2], based on the observation of the five shifts of:

- Operation Supervisors (OS);

- New and experienced control room engineers;

- Operators that work throughout the production site (new and experienced).

Results were discussed with each shift.

\subsection{Project timeline}

The project lasted 12 months with forty days in the field. There were three stages:

- A stage of pre-diagnosis which combined the three above mentioned analyses to understand what was at stake in the management's request;

- A diagnosis stage focused on the ergonomic analyses of the different jobs and a design of the tools to be used for work demographics, in partnership with local management;

- A recommendation stage. 
The outcomes of each stage were presented to the steering committee.

\section{Results}

\subsection{Pre-diagnosis}

\subsubsection{Experienced and new workers with different backgrounds}

Faced to the understaffing situation affecting the site, the group offers to loan two different types of workers:

- Recruits: they have just graduated and have no or little experience. They are called to be trained on-site so as to occupy production and for some of them, engineering jobs; They are present onsite for three years and replaced by other recruits when they leave;

- Engineers with experience in refinery work that can immediately occupy jobs as control room engineers. Their presence is planned until the site shuts down.

Figure 1 shows that experienced workers trained on-site are mostly above 45 years old and that most of those aged between 50 and 54 will retire (retirement age is set at 55) before site shutdown. Moreover, experienced workers aged between 35 and 49 are encouraged to transfer within the group before the site closes down in 2013. Since 2005, about a third of personnel has retired or transferred to another site every year, partly replaced by recruits who have to be trained. Those with most experience say that they feel overworked and that their skills are not valued. They disagree with management on the recruits' training time. As far as they are concerned, experienced loaned workers are not operational immediately as their experience is mostly in refinery, not in sulfur gas extraction. Having the newcomers work in these conditions puts them, the newcomers and the facility at risk.

\subsubsection{A career path closely related to the history of the site}

This change resistance observed by the management must be considered within the larger history of the site, which started production in 1957. As the only such site on French metropolitan territory, it soon became something of a symbol, providing the French with their daily gas. The facility was the epitome of modernity, boosting a region until then largely rural.
One's career path is then devised on local characteristics, first of which is staff stability and cohesiveness: from the creation of the site employees work all their lives on the site, and the job even passes on to the next generation. This is very different from the refinery section of the group, in which mobility is encouraged. The stability of the career is further reinforced by the presence of $\mathrm{H} 2 \mathrm{~S}$, not common in the group's other sites. Careers follow a bottom-to-top progression, starting out as production operator towards more skilled jobs as engineers or even management. Technical skills and expertise justify these trajectories. Learning and training occur over time through companionship where the senior worker trains their replacement. Senior workers can count on a two-year training period in the field for new workers.

\subsubsection{Present-day re-organisations which threaten this career path}

Since 1957 different generations have experienced numerous technologic and organisational changes. However, the staff reductions over the last few years have been badly felt as they radically question the career paths and choices that had guided workers since the early days.

More precisely, in the early 2000s, the two gas treatment lines (desulfurisation on the one hand and separation of gas from oil on the other) were merged, whereas they used to be two physically separated, distinct careers. The AZF disaster which occurred in France in 2001 facilitated this merger by making it compulsory for the site to relocate the control room further away from the operations for safety reasons. A new control room was then created with the merger in mind. In practice, it means that the new organisation made one operation supervisor redundant. The remaining Operation Supervisor must manage the whole setup by himself and also requires engineers to multitask and become versatile to work on both lines. The necessary skills to achieve this versatility were not acquired through the traditional companionship training. As a result, senior experienced workers question how much they really acquired these skills.

The recent arrival of new workers has only further jeopardised the career paths. The training contract has been reduced to 6 months for recruits against two years previously; experienced engineers are directly placed at the control console. This is the context in which site workers have refused to accept engineers 
Age distribution regarding status $(\mathrm{n}=97)$

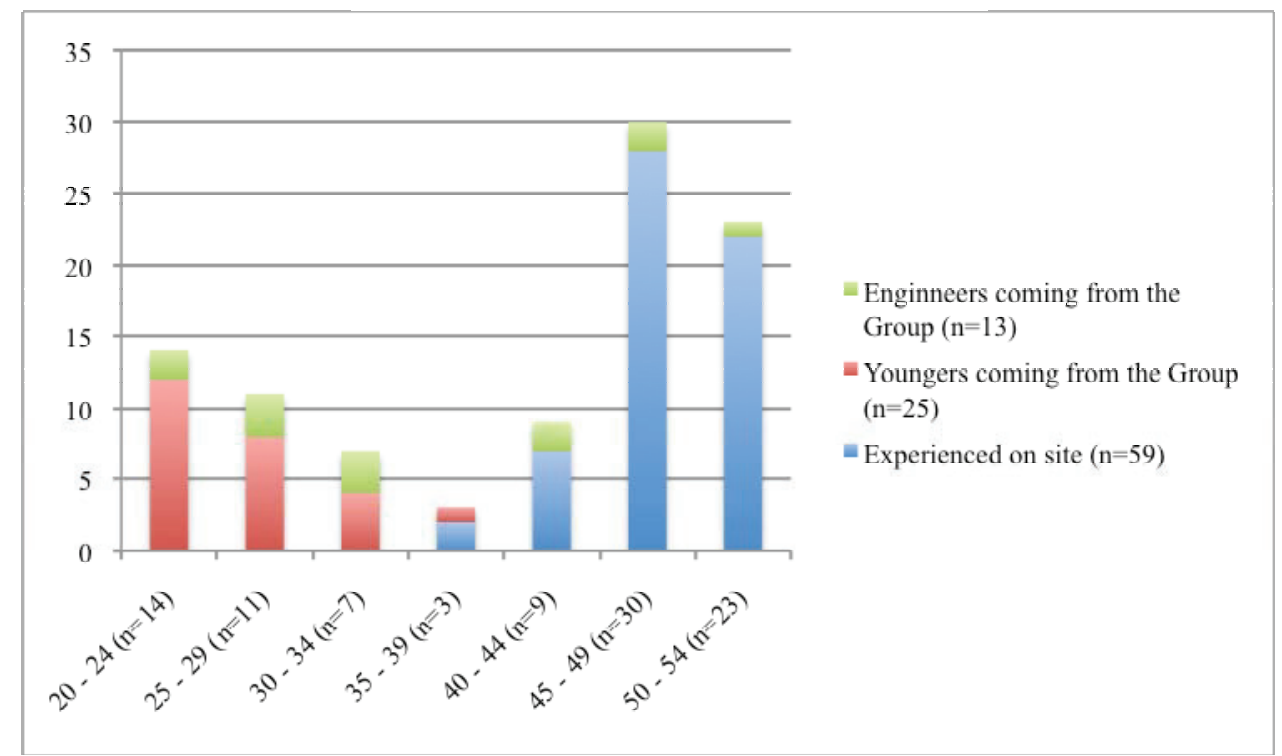

in the control room and remained evasive as to the recruit end of training .

\subsubsection{Produce and train, and daily challenge}

The first stage of investigation made it possible to highlight the following: the gas treatment service is a production department made up of 59\% experienced workers among whom $38 \%$ will leave in the five following years, the rest being likely to leave through transfers. The gas treatment service has also become a training centre due to the regular arrival of recruits whose training outcomes may not be entirely compatible with production objectives. That was not discussed on site between the different stakeholders:

- At the service level, management has to organise recruit training but also that of workers who need to become more versatile. The focus is on operations and training in safe conditions.

- The site management's focus is on quantitative personnel management: training is necessary to ensure minimum staff until shutdown. Site managers must also honour their commitments to corporate, i.e. send back trained recruits after a period of three years.

- At corporate level, the focus is on using specific and transferable skills to train engineers in sulfur gas treatment.

The rest of the project was based on an analysis of the activity carried out by management, engineers and operators (recruits and experienced) to produce and train safely: how and at what cost?

\subsection{Diagnosis}

\subsubsection{Newcomer training}

Newcomer induction is made through a two-step system:

- A theoretical training course made up of general training relative to basic technical knowledge and a health and safety training (12 days). For recruits there is also a more specific training programme focused on the site's production facilities (18 days).

- For recruits only, a 4 to 6 month on-site training takes place, validated by Operation Supervisors.

Several difficulties arise in the on-site induction of newcomers. For engineers, they are directly placed in the control room without any time in the different parts of the facility. It is difficult for them to make connections between the physical locations and their graphic representations on the control consoles. What's more, the facility is aging, and whereas those with most experience in the control room can warn the recruits in the field that activating this or that particular valve may prove difficult, it is obviously not the case for engineers freshly arrived from other sites. They gradually learn the site's peculiarities, but this learning process occurs in a real-life risks context.

For recruits, their learning process can be seen as opportunistic due to the following elements: 
- Present context characterised by constant staff turnover - constant coming and going, lack of operators on site, staff off on training;

- Implicit survival of a companionship-based mode of training. The problem is that this used to last over 2 years and allowed the recruits to be faced with a representative variety of work situations whereas the present period must not exceed 6 months.

Given those characteristics, recruits do not have a designated mentor but a wealth of possible supervisors depending on how the shifts are planned. The encountered events, (start-up, shut-down, incidents...) may or may not trigger briefings / debriefings depending on time constraints and whether experienced workers are available. To experienced mentors, the on-site training always comes on top of the daily training activities, but it may well be complementary or even go against the latter. If such is the case, training becomes very costly to experienced workers who are overworked as well as to recruits left to their own devices. Newcomers can be both an asset and a liability, which had not been anticipated by top management when they developed their quantitative staff management programme.

\subsubsection{Task shifting among site management}

Given the underlying risks for operators themselves and for the facility, local management and experienced operators were led to regulate their activity based on task shifting.

Operation Supervisors leave the control room to perform tasks on the site. This strategy makes it possible to balance the lack of staff and to monitor recruits in the field. However, the shift's management / overseeing tasks are affected by this strategy.

Those overseeing activities are for the most part entrusted to experienced multitask engineers. They add up to their activity as control operator, which does not allow for much anticipated management of the shifts. Training experienced site workers becomes secondary as the emphasis is laid on newcomer training; staff management is done day-by-day and is only possible because site engineers have a very fine knowledge of everybody's skills. Local management solves absence problems based on what "skills" are present that day in the shift. Someone being off-work may cause several changes in the shift's organisation. Those regulations are fragile: they closely depend on the shift's ability to multitask, thus on its training leeway. The departure of an experienced site worker can jeopardise this regulation system. As a consequence, there are great discrepancies between the shifts, determined by the pace at which experienced site workers leave because of transfers or retirement. This had not been anticipated by the HR department.

This type of "hot" regulations remains very dependent on shift configuration and the local management's expertise of how much leeway they have. This particular expertise has not been formalised and is present only "in the minds" of the local management.

A formalising effort was made to assist local management to follow and anticipate staff changes. This tool, easy to design, requires to gather the HR data (age, status, departure date) with the data relative to the workers' skills, obtained from locally available training records. This data merging, carried out shift by shift, makes it possible to map out the skills so as to anticipate replacements.

\subsection{Recommendations}

After presentation to the steering committee, several options for change were agreed upon.

\subsubsection{Designing a tool to follow up and anticipate staff movements}

From the skills mapping, local management collaborated with site computing specialists to design a program that would enable management to follow up on staff mobility as well as to anticipate training needs determined by departures.

Designing this tool implied at first a meeting of local management so as to define the minimum requirements for each position.

\subsection{2. $\quad$ Structuring on-site training}

A training cell was set up. It is steered by three experienced workers, including a former Operation Supervisor. As long as their training is not complete, the recruits can go from the field, where they are assigned within a shift, to the training cell depending on the needs. This cell also allows briefings and debriefings which were difficult to organise in the previous arrangement. It is also possible to review events that may have occurred while other shifts were working, and that recruits have not seen or not completely.

This arrangement emphasises and gives more credit to the position of mentor. 


\subsubsection{Feedback}

A feedback system was offered so as to spot and think about the activities that could place the newcomers in a difficult situation. Indeed in some cases newcomers cannot carry out certain activities in the time limit. Most often these activities were carried out by someone on the next shift, and the solution never reached the person who was originally in trouble. The approach we recommended was designed to spot these issues and bring them out for discussion among staff from all categories so as to generate an organisational training and a transmission of the difficulties within groups.

\section{Conclusion}

In the pre-diagnosis stage, we tried to analyse the top management's decision making process on how to organise a gradual staff reduction. For them, it was a logical decision to make: as production decreases, so should staffing. This number logic actually overlooked the site's reality, namely the real activities carried out by the staff to "hold it together". As underlined by the head of training, former technical director, "the management underestimated the needs in staff and skills by focusing too much on site shudown. The valves were opened, but without any qualitative consideration: which skills were leaving the site?". Indeed, the HR management tools were completely cut out from the work activity.

With this same number-only approach of staffing issues, top management did not realise that the organisational changes they prompted, combined with reduction in personnel, deeply affected the experienced site workers' sense of identity and work culture. What was most impacted were the crucial mechanisms of transfer of professional know-hows from site workers to newcomers. This transmission used to take place over time, included aspects of professional culture and safety know-hows [3] and relied on the moral contract that the experienced site worker would train their successor for the future. The oncoming shutdown, although not causing any direct job losses was another disrupting element.

In such a context, the work organisation could only operate in a degraded mode. The regulations are hot, done on the spur of the moment and are mostly performed by local management and the most experienced workers. They aim to ensure the day-to-day running of the shifts, to avoid the risks of $\mathrm{H} 2 \mathrm{~S}$ con- tamination and accidents that would impact the facility. The departure of any experience worker in one of the shifts questions these regulations. These degraded conditions affecting recruit training programmes (whose learning process may be called opportunistic) have been observed elsewhere, in construction for example [4] and in the healthcare sector [5].

\section{Discussion}

The approach we presented follows on the activity ergonomics as it has been developed for many years by French language ergonomics and more generally by field studies ergonomics [6]. We shall now try to discuss the similarities and differences between our approach and macro-ergonomics.

What was at stake was truly an attempt to analyse a work system [7]. More precisely our contribution aimed to act on three of the five major components identified by Hendrick [8]: Human-job interface technology or work design ergonomics and Humanorganization interface technology or macroergonomic. One of the major innovations of macroergonomics concerns the analysis of the effects of three major socio-technical system elements, the technological subsystem, personnel subsystem and relevant external environment and on the fourth major element the structure of the organisations's work system [9].

Macro-ergonomics is presented as a top-down approach [10]. What we tried was double. First and foremost a bottom-up approach, which, starting from the analysis of operator activity (Operation Supervisors, engineers, field operators and of their utilisation of technical systems and devices then questions how the work and the training are organised. In this respect, it differs from macro-ergonomics.

But this bottom-up approach was combined with an analysis of organisational records, in particular the data relative to changes, shift composition anticipation and management policies. This second approach could well be called top-down and is inspired by macro-ergonomics.

The work that we carried out is then an attempt to combine macro and micro approaches as suggested by Zink [11] and Carayon [12].

Our intervention consisted in reconnecting local and top management by highlighting the work activity and bridging the gap between the different sets of data which they separately used. The implementations of our suggestions was achieved mostly thanks to local management. 


\section{References}

[1] S. Volkoff, A.F. Molinié. Elements for a demographic of work. In J.C. Marquié, D. Pamès Cau Bareille, S. Volkoff (Eds.) Working with age. Taylor and Francis, 1998, 71-90.

[2] F. Daniellou, P. Rabardel Activity-oriented approaches to ergonomics: some traditions and communities. Theoretical issues in Ergonomics science. 2005, 6(5), 353.

[3] E. Cloutier, P.S. Fournier, E. Ledoux, I. Gagnon, C. Vincent-Genod. Percer la culture de métier: une clé essentielle pour les novices afin d'accéder aux savoir-faire de prudence et de métier des travailleurs expérimentés du cinéma. Proceedings of Colloque international les jeunesses au travail : rapports intergénérationnels et dynamiques des groupes professionnels. Brest, France : Université de Bretagne occidentale. French. 2008.

[4] C. Delgoulet, C. Gaudart, K. Chassaing, Entering the workforce and on the-job skills acquisition in the construction sector. Work. (to be published in 2012)

[5] J. Thébault, C. Gaudart, E. Cloutier, S. Volkoff, Transmission of vocational skills between experienced and new hospital workers. Work. (to be published in 2012)

[6] V. de Keyser, Why fields studies? In M. Helander and M. Nagamachi (Eds.), Design for manufacturing and process planning. Taylor and Francis, 1992.

[7] A.S. Imada \& P. Carayon, Editor's comments on this special issue devoted to macroergonmics, Applied Ergonomics 39. 2008, 415-417

[8] H.W. Hendrick, Applying ergonomics to systems: somme documented "lessons learned", Applied Ergonomics 39. 2008, 418-426

[9] H.W. Hendrick, Macroergonomics Analysis of Structure (MAS). In: Stanton, S., Hedge,A., Brookhuis, K., Salad, E., Hendrick, H. (Eds.), Handbook of Human Factors and Ergonomics Methods. CRC Press, Boca Raton, FL, . 2005, 89.189.9 .

[10] E. Haro, B. M; Kleiner, Macroergonomics as an organizing process for systems safety. Applied Ergonomics 39.2008, 450-458

[11] K. Zink. Ergonomics in the past and the future: form a german perspective to an international one. Ergonomics 43 (2000) 7, 920-930.

[12] P. Carayon. Human factors of complex sociotechnical systems. Applied Ergonomics 37. 2006, 525-535. 